\title{
RESEÑA KAHALE CARRILLO, DJAMIL TONY, EL IMPACTO DE LA INDUSTRIA 4.0 EN EL TRABAJO: UNA VISIÓN INTERDISCIPLINAR, ARANZADI THOMSON REUTERS, PAMPLONA, 2020. 423 PP.
}

\author{
Pelayo Jardón Pardo de Santayana* \\ UNED, España
}

Ha sido publicada recientemente por Aranzadi Thomson Reuters esta obra, que versa sobre la repercusión que tiene lo que se conoce como Industria 4.0 o cuarta revolución industrial en el ámbito de las relaciones laborales. Se trata de un proyecto de investigación financiado por la Comunidad Autónoma de la Región de Murcia, a través de la convocatoria de ayudas a proyectos para el desarrollo de investigación científica y técnica por grupos competitivos, incluida en el Programa Regional de Fomento de la Investigación Científica y Técnica (Plan de Actuación 2019) de la Fundación Séneca-Agencia de Ciencia y Tecnología de la Región de Murcia. La obra ha sido dirigida por Djamil Tony Kahale Carrillo, profesor titular de Derecho del Trabajo y de la Seguridad Social de la Universidad Politécnica de Cartagena (UPTC). De carácter eminentemente interdisciplinar, aúna los distintos puntos de vista de trece expertos de distintas universidades españolas, con textos sólidamente estructurados, que proporcionan información básica sobre las distintas materias, pero también específica, tanto científico-doctrinal como, en su caso, jurisprudencial; lo cual los hace tan accesibles al neófito como interesantes para el iniciado.

Cuenta con un prólogo del catedrático y magistrado del Tribunal Supremo, Antonio Sempere Navarro, quien, amén de trazar una síntesis introductoria sobre las aportaciones de cada uno de los autores, esboza atinadas reflexiones sobre aspectos tales como las consecuencias sociolaborales de las medidas sanitarias de contención de la COVID-19, la ordenación del tiempo de trabajo y el derecho a la desconexión digital fuera del ámbito laboral.

\footnotetext{
* Correspondencia a: Pelayo Jardón Pardo de Santayana. Santa Rosa, 10, 1.D, San Lorenzo del Escorial, Madrid, España. — mikel. pelayojardon@gmail.com — https: //orcid.org/0000-0002-8235-8510

Cómo citar: Jardón Pardo de Santayana, Pelayo. (2021). «Reseña Kahale Carrillo, D.T. (Dir.), El impacto de la industria 4.0 en el trabajo: una visión interdisciplinar, Aranzadi Thomson Reuters, Pamplona, 2020. 423 pp.); Lan Harremanak, 45, 313-330. (https: //doi. org/10.1387/lan-harremanak.22770)

Recibido: 01 mayo, 2021; aceptado: 03 mayo, 2021.

ISSN 1575-7048 - eISSN 2444-5819 / (c) 2020 UPV/EHU
}

(c) Esta obra está bajo una licencia

Creative Commons Atribución 4.0 Internacional 
En el primer capítulo, Ángel Arias Domínguez diserta sobre la adecuación de las instituciones jurídico laborales a la globalización, el uso de robots y el teletrabajo. A este respecto, analiza las ventajas, pero también los problemas clave y los retos que plantea el teletrabajo: especialmente, la necesidad de que el Derecho, so pena de caer en el abismo de la obsolescencia, afronte la crisis de la empresa centralizada tradicional y adapte — no sólo cosméticamente- su regulación a tales realidades. Además, examina desde un punto de vista jurisprudencial el problema de la sustitución de puestos de trabajo por programas informáticos.

A cargo de Francisco González Díaz, el segundo capítulo está dedicado al uso de los sistemas de videovigilancia en el contexto de la relación laboral, así como a la incidencia que, en los derechos de los trabajadores, tiene la consideración de las grabaciones de imágenes y sonidos como datos de carácter personal protegidos. El autor va desgranando los diferentes aspectos de la cuestión: las medidas de protección de datos contenidas en la Ley Orgánica 3/2018, de 5 de diciembre, de Protección de Datos Personales y garantía de los derechos digitales; en el Reglamento (UE) 2016/679 del Parlamento Europeo y del Consejo, de 27 de abril de 2016, relativo a la protección de las personas físicas en lo que respecta al tratamiento de datos personales y a la libre circulación de estos datos; el control de la videovigilancia y grabación de sonidos en el Estatuto de los Trabajadores; y, en fin, el Dictamen 4/2004 referente al tratamiento de datos personales mediante vigilancia por videocámara del grupo del artículo 29 de la Agencia Espańola de Protección de Datos. Partiendo de tales presupuestos, y tras analizar la legitimidad del empresario para el tratamiento de datos obtenidos a través de sistemas de videovigilancia, de acuerdo con los fines perseguidos y el principio de proporcionalidad, Francisco González Díaz hace un pormenorizado repaso de la jurisprudencia sobre el tema emanada del Tribunal Constitucional, del Tribunal Supremo y del Tribunal Europeo de Derechos Humanos.

María Elisa Cuadros Garrido aborda, en tercer lugar, el problema de los trabajos precarios y de los falsos autónomos dentro del área de prestación de servicios mediante plataformas digitales. El estudio se centra concretamente en las plataformas digitales directas de servicios, cuya relación jurídica con los trabajadores se considera desde la Directiva n. ${ }^{\circ}$ 2019/1152 del Parlamento y del Consejo como respuesta normativa comunitaria al contrato de trabajo atípico. Tras examinar resoluciones del Tribunal de Justicia de la Unión Europea; de algunos países, como Francia, Reino Unido o Alemania; y, en lo tocante a la situación española, sentencias de los Tribunales Superiores de Justicia y del Tribunal Supremo referidas a plataformas como Glovo o Deliveroo, la autora concluye en la necesidad de otorgar un estatus adecuado a ese colectivo de trabajadores.

Belén Fernández Collados examina seguidamente la adecuación de la negociación colectiva a las condiciones impuestas por la Industria 4.0 y ello en lo que respecta a tres aspectos de la relación laboral. De un lado, la influencia de la digitaliza- 
ción industrial en el acceso al empleo y las aspiraciones de promoción al trabajo. Por otra parte, en lo atinente a los cambios en la organización del trabajo, esto es: en el sistema de producción; en la necesidad de una correcta utilización por parte del trabajador de las nuevas tecnologías; en el control y seguimiento de la prestación de servicios; y en la actividad sindical. Tras ello, pasa a enjuiciar la repercusión de la Industria 4.0 en la salud de los trabajadores y en la prevención de riesgos laborales.

Djamil Kahale evalúa en el quinto capítulo la repercusión de los adelantos tecnológicos en el derecho a la huelga en Espańa, y particularmente en lo que se refiere a la sustitución de la fuerza productiva de los huelguistas por la robótica y la inteligencia artificial. Amén de señalar las posibles fricciones de esta cuestión con la libertad de empresa, Kahale traza una visión panorámica de las distintas posiciones doctrinales y de las coincidencias y divergencias de criterios entre el Tribunal Supremo y el Tribunal Constitucional.

Fulgencio Pagán consagra el sexto capítulo al control que se puede realizar sobre la persona del trabajador por medio de instrumentos biométricos, los cuales permiten su identificación a través de fenómenos o procesos biológicos como las huellas dactilares, las líneas de las manos, el iris, la retina, el ADN, los rasgos faciales o incluso la forma de andar o hablar y la firma. A la descripción de estos medios, Pagán añade referencias normativas de la Constitución Española, del Estatuto de los Trabajadores y de la Ley Orgánica 3/2018, así como de algunos precedentes jurisprudenciales.

Por su parte, Carmen Sánchez Trigueros reflexiona sobre el problema de la hiperconectividad laboral y los riesgos que la merma del derecho a la desconexión digital puede ocasionar. En especial, focaliza su atención en el artículo 88 de la ya citada Ley Orgánica 3/2018, precepto tan loable en su intención como insuficiente en su contenido, debido a su carácter de mera declaración programática, pendiente, por ello, de revisión y complemento. En esta dirección, la autora profundiza en el derecho a la intimidad personal y familiar; y también en la importancia que, mor de tales carencias normativas, cumple tanto el empleador como la negociación colectiva al definir los caracteres, límites y garantías del derecho a la desconexión digital.

En el capítulo octavo, Carolina San Martín examina la falta de claridad de la que a menudo adolecen las lindes que separan el tiempo de trabajo y el tiempo de descanso, un problema de por sí complejo, agudizado por las recientes modificaciones normativas. Tras glosar los artículos 87 y 88 de la LOPD, la autora propone algunas soluciones, como la creación de protocolos empresariales internos para la desconexión o la adaptación del tiempo de trabajo a las responsabilidades familiares, en lo que se ha dado en llamar "jornada a la carta». Reflexiona además acerca de la mayor vulnerabilidad femenina en lo tocante al derecho al descanso, debido a la asunción por parte de la mujer de las tareas domésticas; y del consiguiente imperativo de propiciar modelos más igualitarios de corresponsabilidad familiar. 
En otro orden de cosas, José María Ríos Mestre considera el tema de la admisibilidad y valoración de la prueba en el procedimiento laboral mediante instrumentos electrónicos, como los sistemas de grabaciones de voz, de videovigilancia y los dispositivos GPS. Desgrana de igual modo la normativa aplicable a los datos almacenados en soporte digital, como el correo electrónico y los sistemas de mensajería instantánea.

Richard Mababu destaca en el capítulo décimo la importancia que tiene la adquisición por parte del trabajador de las competencias necesarias para el uso de las nuevas tecnologías. A este respecto, señala la interacción experimental y, sobre todo, la formación como vías principales para dotar a las personas de esas herramientas exigidas en sus puestos de trabajo. Tras ponderar las distintas dimensiones que han de ser tenidas en cuenta para optimizar el desarrollo formativo y los principales grupos de competencias claves para el emprendimiento, corona su estudio con una serie de recomendaciones deducidas de los datos obtenidos de una encuesta realizada a más de trescientos directivos de empresa.

Manuel Hernández Pedreño, por su parte, utiliza como perspectiva de estudio las áreas sociales del conocimiento (Economía, Derecho, Educación, Sociología, Psicología); y ello a través de la revisión de las principales investigaciones realizadas acerca de la Industria 4.0, localizadas en el portal de Dialnet. El autor expone un análisis formal y un análisis de contenido de cincuenta y ocho artículos publicados en la última década, que acompaña de tablas, las cuales ayudan a formarse una visión de conjunto sobre la materia.

En el capítulo duodécimo, Pedro Ruiz considera el potencial transformador de la tecnología en lo que atañe a cuestiones diversas, como la generación de riqueza, la eficiencia energética y las emisiones contaminantes o las ventajas e inconvenientes de su regulación. Aborda igualmente la trascendencia que tendrá la Industria 4.0 en el futuro de las profesiones, el riesgo de automatización de algunas de ellas y las más que probables necesidades de reciclaje y recualificación de muchos trabajadores. Con base en estas premisas, aventura el futuro de las profesiones que tendrán una mayor demanda, así como la adaptación que habrá de operarse en los programas universitarios para adaptarlos a las necesidades formativas de los estudiantes.

Finalmente, Olga García Luque estudia el proceso de digitalización de la economía española desde el prisma de la difusión de la tecnología digital entre las empresas. Tras señalar las dificultades relativas a la medición de la economía digital, compara el proceso de transformación digital en Espańa con el de otros países, a partir de diversos indicadores, como las inversiones en investigación y desarrollo, el registro de patentes relacionadas con la inteligencia artificial, el número de tarjetas SIM para la comunicación entre máquinas (M2M) o la difusión del comercio electrónico. En el entendimiento de que favorece la productividad y, por ende, la competitividad, la autora encarece la necesidad de 
aprovechar este proceso de digitalización en beneficio de la industria y la economía españolas, si bien alerta de determinados riesgos inherentes a tales cambios, como los problemas de seguridad digital, la desigualdad en el uso de internet o la automatización del trabajo.

Recapitulando, la obra que nos presenta el profesor Kahale, con el apoyo del elenco de profesores que lo acompaña, constituye un libro de obligada consulta para todas aquellas personas que quieran adentrarse desde un punto de vista interdisciplinar en el mundo de la cuarta revolución industrial. 


\section{Egin-asmo ditugun aztergaiak}

46. zk. XXI. mendeko Ongizate Estatua

47. zk. 


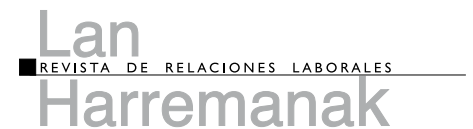

\section{Argitaratutako aleak}

1. zbk.: Lan-denbora.

2. zbk.: Lana XXI. mendean.

3. zbk.: Ekoizpen harremana eta ekoizpen artikulazioa.

Berezia: Mintegia: Lan Zientzietako lizentziatura erantzea UPV/EHU-n.

4. zbk.: $\quad$ Enplegu beterantz? Lan-politikak Europan.

5. zbk.: Lan-harremanak garapen bidean. Aldaketak enpleguan eta gizarte-babesean.

Berezia: Lan osasuna.

6. zbk.: Desindustrializazioa eta birsortze sozioekonomikoa.

7. zbk.: Laneko jazarpen psikologiko edo mobbing-ari buruzko gogoetak eta galderak.

Berezia: UPV/EHU ko Lan Harremanen Unibertsitate Eskolak ematen duen Lan eta Gizarte

Segurantzaren Zuzenbideari buruzko egungo eztabaiden Bigarren Jardunaldiak.

8. zbk.: Lan-merkatua eta inmigrazioa.

9. zbk.: Etika eta enpresa.

10. zbk.: Pentsioak.

11. zbk.: Lan merkatua eta ijitoen ingurunea.

12. zbk.: Globalizazioa eta Lan Merkatua.

13. zbk.: Emakumeak eta Lan Merkatua.

Berezia: Beste Globalizazio baterako tokiko proposamenak. Globalizazio ekonomiko, Eskubide Sozial eta Lan Arauei buruzko seminarioa.

14. zbk.: $\quad$ Enpresen gizarte-erantzunkizuna.

15. zbk.: Dependentziaren inguruko eztabaida.

16. zbk.: Malgutasuna versus Egonkortasuna.

17. zbk.: Lan harremanetako eta giza baliabideetako ikasketak eta lan-praktikak.

18. zbk.: Lanbidea eta Familia Zaintza.

19. zbk.: Espainiko enpresa transnazionalak eta Korporazioen Erantzukizun Sozialak.

20-21. zbk.: Krisiaren eraginak arlo soziolaboralean.

22. zbk.: Gizarteratzea eta enplegu politikak.

23. zbk.: $\quad$ Emakume langileen Laneko Segurtasun eta Osasuna.

24. zbk.: Adina, erretiroa eta lan merkatuan irautea.

25. zbk.: Berdintasuna eta diskriminaziorik eza lan harremanetan, generoa dela medio.

26. zbk.: Lan eta gizarte eskubideak krisi garaietan.

27. zbk.: Negoziazio kolektiboa: lehiakortasuna eta soldatak.

28. zbk.: Antolakuntzak erronka globalaren aurrean.

29. zbk.: Gizarte inklusiboa lortzearen erronka. Sarturen 25. urteurrena.

30. zbk.: $\quad$ Udal Ekonomiko-Administratibo Auzitegien IX. Topaketa.

31. zbk.: Langile pobrezia.

32. zbk.: Lan-harremanen erronka gizarte ekonomia solidarioaren aurrean.

33. zbk.: Enpresa transnazionalen boterearekiko erresistentzia eta bestelako proposamenak.

34. zbk.: $\quad$ Lan denboraren murrizketa. Langabezia murrizteko proposamena.

35. zbk.: Negoziazio kolektiboa, langileen parte-hartzea eta enpresaren alderdi ekonomikoen eta kontabilitate alderdien sindikatu-kontrola. 
36. zbk.: $\quad$ Administrazio Publikoetan laneko alderdi juridikoak.

37. zbk., Berezia: Hezkuntza Berrikuntza Lan Harreman eta Giza Baliabideen Graduan.

38. zbk.: Berdintasun Lege Oerganikoa (X. urteurrena).

39. zbk.: $\quad$ Lanaren Nazioarteko Erakundearen (LANE) mendeurrena

40. zbk.: $\quad$ Erretiro pentsioak eta gizarte babesa

41. zbk.: Ekonomia kolaboratiboa

42. zbk. Digitalizazioa, uztartzea eta lana merkatalgai bezala

43. zbk. Enplegua eta gizarteratzearen arteko harremanak: eraldaketak eta etorkizuneko erronkak

44. zbk. Negoziazio kolektiboa eta lan osasuna eta segurtasuna

45. zbk. Langileen estatutua: aldaketa aukerak 


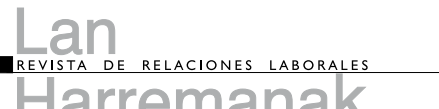

\section{Próximos temas previstos}

N. 46: $\quad$ Estado de Bienestar del siglo XXI

N.o 47 : 


\section{Números publicados}

N. ${ }^{\circ}$ 1: $\quad$ El tiempo de trabajo.

N. ${ }^{\circ}$ 2: $\quad$ El trabajo en el siglo xxi.

N. ${ }^{\circ}$ 3: $\quad$ Relación productiva y articulación de la producción.

Especial: Seminario sobre la implantación de la licenciatura en Ciencias del Trabajo en la UPV/EHU.

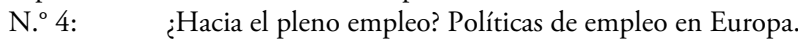

N. ${ }^{\circ}$ 5: Las relaciones laborales en evolución. Cambios en el empleo y la protección social.

Especial: Salud laboral.

N.ำ: Desindustralización y regeneración socioeconómica.

N..$^{\circ}$ : $\quad$ Reflexiones y preguntas sobre el acoso psicológico laboral o mobbing.

Especial: Segundas Jornadas sobre cuestiones de actualidad del Derecho del Trabajo y de la Seguridad Social de la Escuela Universitaria de Relaciones Laborales de la UPV/EHU.

N. ${ }^{\circ}$ 8: $\quad$ Mercado de trabajo e inmigración.

N. 9: $\quad$ Ética y empresa.

N. ${ }^{\circ} 10: \quad$ Pensiones.

N. ${ }^{\circ} 11: \quad$ Mercado de trabajo y mundo gitano.

N. ${ }^{\circ} 12: \quad$ Globalización y mercado de trabajo.

N. ${ }^{\circ} 13: \quad$ Mujeres y mercado de trabajo.

Especial: Propuestas locales para otra Globalización. Seminario sobre Globalización Económica, Derechos Sociales y Normas Laborales.

N. ${ }^{\circ}$ 14: Responsabilidad social empresarial.

N. ${ }^{\circ}$ 15: $\quad$ El debate sobre la dependencia.

N. ${ }^{\circ}$ 16: $\quad$ El debate sobre la flexiseguridad.

N. ${ }^{\circ}$ 17: Los estudios y las prácticas profesionales en Relaciones Laborales y Recursos Humanos.

N. ${ }^{\circ}$ 18: $\quad$ Empleo y cuidados familiares.

N. ${ }^{\circ}$ 19: $\quad$ La empresas transnacionales españolas y la Responsabilidad Social Corporativa.

N. ${ }^{\circ}$ 20-21: Aspectos sociolaborales de la crisis.

N. ${ }^{\circ} 22: \quad$ Inclusión social y políticas de empleo.

N. ${ }^{\circ}$ 23: $\quad$ La Seguridad y Salud Laboral de las mujeres trabajadoras.

N. ${ }^{\circ}$ 24: $\quad$ Edad, jubilación y permanencia en el mercado de trabajo.

N. ${ }^{\circ}$ 25: Igualdad y no discriminación por razón de género en las relaciones laborales.

N. ${ }^{\circ}$ 26: $\quad$ Derechos laborales y sociales en tiempos de crisis.

N. ${ }^{\circ}$ 27: $\quad$ Negociación colectiva: competitividad y salarios.

N. ${ }^{\circ} 28: \quad$ Las organizaciones ante el reto global.

N. 29 : El reto de una sociedad inclusiva. 25 aniversario de Sartu.

N. 30 : IX Encuentro de Tribunales Económico-Administrativos Municipales.

N. ${ }^{\circ}$ 31: $\quad$ Pobreza trabajadora.

N. ${ }^{\circ}$ 32: Las relaciones laborales ante el reto de una economía social y solidaria.

N.o 33: $\quad$ Propuestas y resistencias al poder de las empresas transnacionales.

N. ${ }^{\circ}$ 34: La reducción del tiempo de trabajo. Una propuesta para reducir el desempleo.

N. ${ }^{\circ}$ 35: Negociación colectiva, participación de los trabajadores y trabajadoras y control sindical de los aspectos económicos y contables de la empresa.

N. 36: Aspectos jurídicos-laborales en el marco de las Administraciones Públicas.

N. ${ }^{\circ}$ 37: Especial: Innovación educativa en el Grado de Relaciones Laborales y Recursos Humanos. 
N. 38: $\quad$ Ley Orgánica de Igualdad (X. aniversario).

N. ${ }^{\circ}$ 39: $\quad$ Centenario de la Organización Internacional del Trabajo (OIT)

N. ${ }^{\circ}$ 40: Pensiones y protección social

N. ${ }^{\circ}$ 41: Economía colaborativa

N. ${ }^{4}$ 42: Trabajo digital y Relaciones Laborales

N. ${ }^{\circ}$ 43: Las relaciones entre empleo e inclusión social: transformaciones y retos de futuro

N. ${ }^{\circ}$ 44: $\quad$ Negociación colectiva y seguridad y salud en el trabajo

N. ${ }^{\circ}$ 45: Estatuto de los Trabajadores: Perspectivas de cambio 


\section{Eraikuntza Hastapenak}

Lan Harremanak. Revista de Relaciones Laborales Euskal Herriko Unibertsitateko Lan Harremanetako UEren ekimenez sortu zen eta gaur egun Lan Harreman eta Gizarte Langintza Fakultatearen (Bizkaiako Campusa) ardurapean dago. Bere helburuak hauek dira:

1. Lanaren fenomenoa aztertzea jakintzagai askoren ikuspuntutik.

2. Hausnarketa- eta elkarrakzio-topagunea sortzea, non administrazio-, gizarte- zein ekonomia-sektore ezberdinak ideia bateragarriak sortu eta elkarrekin aldatzeko aukera izango duten.

3. Ideien bidez enplegua eta gizarte inklusioa hobetzea.

\section{Principios Fundacionales}

Lan Harremanak. Revista de Relaciones Laborales nació por iniciativa de la EU de Relaciones Laborales (UPV/EHU) y actualmente es la Facultad de Relaciones Laborales y Trabajo Social (Campus de Bizkaia) la encargada de la misma. Los objetivos de la revista son:

1. Estudiar el fenómeno del trabajo desde una perspectiva interdisciplinar.

2. Crear un espacio de encuentro y reflexión donde los distintos sectores económicos, sociales y de la Administración puedan intercambiar y generar ideas convergentes.

3. Contribuir por medio de las ideas a la mejora del empleo y de la inclusión social. 


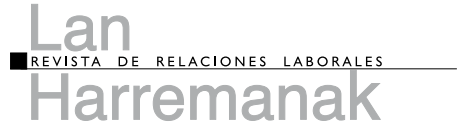

\section{Artikuluak bidaltzeko arauak}

\section{Baldintza orokorrak}

Artikuluak originalak eta argitaragabeak izan behar dira. Autoreak, bere identifilkazio datuekin batera, bere orcid kodea jarri behar du.

Artikuluek gehienez 25 orrialdeko luzera izango dute (Times New Roman, 12, lerroarteko espazio sinplea).

Artikuluaren izenburua idatzitako hizkuntzan eta ingelesez idatziko da. Horrekin batera, artikuluaren laburpena bidaliko da jatorriko hizkuntzan eta ingeles, eta egileak Euskal Autonomia Erkidekoak direnean, euskaraz ere bai. Horren gutxi beherako luzera 150 hitzekoa izango da.

Artikuluek 3 eta 5 arteko hitz gako izango dituzte (gaztelaniaz, euskaraz eta ingelesez), lanaren edukiaren ideia azkarra eman eta haren katalogazioa erraztuko dutenak.

Sumarioa ere aurkeztu behar da. Bertan eta artikuluan zehar, atalak eta azpiatalak zenbaturik azaldu behar dira ((1.; 1.1.; 1.1.1; a) b)).

Genero berdintasunaren ikuspuntutik, hizkuntza inklusiboa erabiltzea gomendatzen da.

Artikuluen proposamenak Open Journal System (OJS) aplikazioaren bidez jasoko dira, webgune honetan: https://www.ehu.eus/ojs/index.php/ Lan_Harremanak/information/authors

\section{Estiloari buruzko oinarrizko arauak}

Arau orokor gisa, eta jarraian adieraziko diren salbuespenak salbu, artikulua testu normalean idatziko da oso-osorik. Hori dela eta, kontzeptu edo ideiaren bat nabarmentzeko hizki lodiak, azpimarratuak edota larriak erabiltzea baztertzen da.

Siglak eta akronimoak hizki larriz idatziko dira eta horien arteko banaketarako ez da punturik erabiliko (EEBB, EE.BB.-ren ordez; CCOO, CC.OO.-ren ordez; LANE, L.A.N.E.-ren ordez).

Kakotxen arteko hizki etzanak hitzez hitzeko adierazpen eta esaldietarako bakarrik erabiliko dira. 
Aipamen luzeak, bi lerro baino gehiagokoak arau orokor gisa, kakotxik gabe egongo dira, hizki zuzenean eta testu normala baino gorputz bat baxuago. Goian eta behean bazterrarekiko 3 milimetroko espazioa utziko da paragrafo osoan.

Kakotxik gabeko hizki etzanak egunkari edo liburuen izenburuetarako, beste hizkuntza bateko hitzetarako, edota hitz edo adierazpenen bat nabarmentzeko erabiliko dira.

Hizki zuzenean eta kakotxen artean, ohiko hizkuntzaren arabera (hitzaren hitzez hitzeko esanahiarekiko aldea adierazteko).

Taulak, laukiak eta irudiak hurrenkera jarraituz zenbakituko dira,arabiar zenbakiak erabiliz. Idazpuru labur bat izango dute eta testuan haiei aipu egingo zaie (1 taula, 1 laukia, 1 irudia, etab.).

\section{Erreferentzia bibliografikoarentzat formatua}

Testuan sartutako erreferentzia bibliografikoak bi eratan aurkeztuko dira, testuinguruaren eta paragrafoaren idazkeraren arabera:

a) Autorearen izena parentesi artean, urtea eta orrialdearen zenbakia, adibidez, (White, 1987: 43) edo (Guerin et al., 1992: 23-34).

b) Autorearen izena, eta parentesi artean, urtea, adibidez, White (1987) edo Guerin et al. (1992).

Erreferentzia bibliografikoak alfabeto hurrenkeraren arabera sartuko dira lanaren amaieran, eta kronologikoki egile beraren lan bat baino gehiago dagoenean. Aldizkarien izenak eta liburuen izenburuak hizki etzanetan jarriko dira. Genero berdintasun eremuko gomendioak betetzearren, ahal den neurrian, egileen izen osoa jarriko da eta ez hasierako hizkia bakarrik.

— Aldizkarietako artikuluak: Arnull, Anthony (2006): «Family reunification and fundamental rights", European Law Review, 5, 611-612.

— Liburuak: Villoria, Manuel eta Del Pino, Eloísa (1997): Manual de Gestión de los Recursos Humanos en las Administraciones Públicas, Madril, Tecnos

— Liburuetako kapituluak: Domínguez, Fernando (1996): «Gestión planificada de Recursos Humanos (Modelo de una empresa multinacional)», Ordóñez, Miguel (arg.), Modelos y Experiencias Innovadoras en la Gestión de los Recursos Humanos, Bartzelona, Gestió 2000, 343-357. 


\section{Normas para la entrega de artículos}

\section{Condiciones generales}

En cuanto a la prevención de posibles malas prácticas, los autores deben garantizar que los trabajos entregados son originales e inéditos y deben evitar tanto el plagio como el autoplagio. Se entiende por plagio la presentación de un trabajo ajeno como propio; la inclusión de frases, conceptos o ideas de otros sin citar la procedencia o citando de manera incorrecta; el uso de citas literales o parafraseada sin indicar la fuente. El autoplagio es la reutilización redundante del trabajo propio, habitualmente sin citarlo de manera adecuada. Tenga presente que los manuscritos son sometidos a procesos de valoración de plagio a través del sistema Similarity Check.

La extensión de los artículos no deberá sobrepasar las 25 páginas (Times New Roman, cuerpo 12 e interlineado sencillo), como norma general. En la medida de lo posible, se evitarán los dibujos, gráficos, figuras, tablas...

El artículo debe incorporar el ORCID del autor.

Los artículos se acompañarán de un abstract o resumen en castellano e inglés, además de en euskara cuando los autores o autoras sean de la Comunidad Autónoma del País Vasco, con una extensión aconsejada próxima a las 150 palabras.

Los artículos deberán incluir entre 3 y 5 palabras clave (castellano, inglés y euskara si las autoras o autores tienen su residencia en la Comunidad Autónoma Vasca) que proporcionen una idea rápida del contenido del trabajo y faciliten su catalogación.

El título del artículo también figurará en inglés.

Los apartados y subapartados del artículo deberán ir numerados (1.; 1.1.; 1.1 .1 ; a) b)).

Se recomienda la utilización de lenguaje inclusivo desde la perspectiva de igualdad de género.

Para enviar un artículo deberá, en primer lugar, darse de alta como autor la y después subir el artículo original en formato Word. Puede registrarse aquí, marcando la casilla de «Autor/a». 
Para la revisión por pares externa según método doble ciego, los documentos enviados deben carecer de señas que identifiquen a las personas autoras; es decir, no deben estar firmados y en los metadatos del documento no debe haber mención a la autoría (en word 2019: Archivo > Comprobar si hay problemas > inspeccionar documento $>$ Inspeccionar $>$ Propiedades del documento e información personal > Quitar todo).

Normas básicas de estilo

Como principio general, y salvando las excepciones que se comentarán a continuación, el cuerpo del artículo se escribirá íntegramente en texto normal. Por ello, se rechaza la utilización de negritas, subrayados y/o palabras en mayúsculas para resaltar un concepto o idea.

Las siglas y acrónimos se escribirán en letras mayúsculas sin que medien puntos de separación entre las mismas (EEUU en lugar de EE. UU.; CCOO en lugar de CC.OO.; OIT en lugar de O.I.T; etc.).

Para citas textuales breves insertas en el cuerpo del texto se utilizarán las comillas sin cursiva ni subrayado.

Las citas textuales extensas, de más de dos líneas como norma general, irán sin comillas, en letra recta, un cuerpo más bajo que el texto normal, dejando un espacio arriba y abajo y poniendo un espacio en todo el párrafo de tres milímetros hacia el margen.

Las cursivas sin comillas se utilizarán para títulos de periódicos, libros, palabras en idiomas distintos aquel en el que esté escrito el artículo, que no sean de uso aceptado, o para destacar una palabra o expresión.

Las palabras entre comillas en letra recta, según el uso en el lenguaje cotidiano (para expresar una distancia con el significado literal de la palabra).

Las tablas, cuadros y figuras irán numeradas consecutivamente con caracteres arábigos, llevando un encabezamiento conciso, haciendo referencia a ellas en el texto como (tabla 1, cuadro 1, figura 1, etc.).

Formatos de referencias bibliográficas

La revista Lan Harremanak utiliza el estilo Harvard (autor-año) para citas bibliográficas del texto. Las citas bibliográficas incluidas en el texto se presentarán de dos formas, dependiendo del contexto y de la redacción del párrafo en el que se incluyen: 
a) Indicando entre paréntesis el nombre del primer autor o autora, seguido del año y del número de página, por ejemplo (White, 1987: 43) o (Guerin et al., 1992: 23-34).

b) Indicando el nombre del autor o autora y, entre paréntesis, el año, por ejemplo: White (1987) o Guerin et al. (1992).

La revista Lan Harremanak utiliza el estilo APA (American Psychological Association) para las referencias bibliográficas. Se incluirán ordenadas alfabéticamente al final del trabajo, y cronológicamente en el caso de varios trabajos del mismo autor o autora. Se pondrán en cursiva el nombre de las revistas y el título de los libros. Se podrán indicar links a los documentos citados, indicando a continuación y entre paréntesis la fecha del último acceso. En cumplimiento de las recomendaciones en materia de igualdad, se identificará, en la medida de lo posible al autor o autora con el nombre completo y no únicamente con la inicial del nombre.

Las referencias bibliográficas se incluirán ordenadas alfabéticamente al final del trabajo, y cronológicamente en el caso de varios trabajos del mismo autor o autora. Se pondrán en cursiva el nombre de las revistas y el título de los libros. Se podrán indicar links a los documentos citados, indicando a continuación y entre paréntesis la fecha del último acceso. En cumplimiento de las recomendaciones en materia de igualdad, se identificará, en la medida de lo posible, al autor o autora con el nombre completo y no únicamente con la inicial del nombre.

- Artículos en revistas:

Tezanos Tortajada, Jose Félix (1983) «Satisfacción en el trabajo y sociedad industrial: una aproximación al estudio de las actitudes hacia el trabajo de los obreros industriales madrileños», Reis: Revista española de investigaciones sociológicas, 22, 27-52. Disponible en: https://dialnet.unirioja.es/descarga/articulo/52969.pdf (Accedido: 4-3-2019)

- Libros:

Villoria, Manuel y Del Pino, Eloísa (1997) Manual de Gestión de los Recursos Humanos en las Administraciones Públicas. Madrid: Tecnos.

- Capítulos de libros:

Domínguez, Fernando (1996) «Gestión planificada de Recursos Humanos (Modelo de una empresa multinacional)", en Ordóńez, Miguel (ed.), Modelos y Experiencias Innovadoras en la Gestión de los Recursos Humanos. Barcelona: Gestió 2000, 343-357.

Consultar directrices para autores en:

https://www.ehu.eus/ojs/index.php/Lan_Harremanak/about/ submissions\#authorGuidelines 